\title{
MULTIBAND HANDSET ANTENNAS BY MEANS OF GROUNDPLANE MODIFICATION
}

\author{
Jaume Anguera $^{*(1,2)}$, Arnau Cabedo ${ }^{(2)}$, Cristina Picher ${ }^{(1)}$, \\ Iván Sanz $^{(1)}$, Miquel Ribó ${ }^{(2)}$, Carles Puente ${ }^{(1)}$ \\ (1) Technology and Intellectual Property Rights Department \\ Fractus, Barcelona - Spain \\ (2) Communications and Signal Theory Department \\ Universitat Ramon Llull, Barcelona - Spain \\ Jaume.anguera@fractus.com
}

\begin{abstract}
A technique consisting in designing the groundplane of a handset antenna is presented. The technique is applied to PIFA antennas to show how the bandwidth can be enhanced. Particularly, a dual-band PIFA operating at GSM900MHz and GSM1800MHz is expanded up to quad-band and hexa-band operation by means of groundplane design. Results for antenna efficiency show that the proposed technique can be applied to design multi-band antennas for handset phones.
\end{abstract}

Keywords- PIFA antenna, handset antennas, multi-band operation

\section{INTRODUCTION}

The rapid growth of the mobile phone business has opened an interesting field for antenna designers: handset antennas, i.e., antennas embedded in cell-phones. The main electrical features of these antennas are small size and multi-band operation. Cellphones have evolved from former dual-band designs (ex: GSM900 and $1800 \mathrm{MHz}$ ) to more sophisticated designs such as those having GSM850, 900, 1800, 1900 and even the $3 \mathrm{G}$ UMTS system, for example. The number of cell-phones sold over the world manifests a huge demand.

Initial designs were based on external antennas such as for example monopoles or helicoids. Nowadays, the big phone manufacturers are migrating to internal antennas. Advantages of these sorts of antennas are their robustness, good aesthetics as they are embedded into the phone platform and low SAR compared with external monopoles (especially different at higher frequencies).

It has been shown that when the groundplane length is approximately $0.4 \lambda$, bandwidth can be enhanced [1-10]. This represents an interesting finding for multi-band mobile handset antennas covering several services [1]. Groundplane dimensions are fixed by the PCB (Printed Circuit Board) of the handset phone. This is also fixed for product marketing purposes depending on the phone model. The combination of both of these issues requires that antenna engineers directly address the dimensions of the groundplane. For short PCBs (70-100mm length), bandwidth at low frequencies (GSM for example) is quite narrow, achieving in the best cases $7-8 \%$ at $\mathrm{SWR}=3$. The objective is how the groundplane can be designed to squeeze more bandwidth from the whole structure.

The paper is divided as follows: section ground-plane design presents the proposed technique in order to enhance the bandwidth of a reference PIFA. The reference PIFA is designed to cover the standards GSM900 and $1800 \mathrm{MHz}$. In section results, 
experimental data is shown to reveal how the bandwidth can be enhanced. Finally, section conclusions, outlines the most interesting findings of this research.

\section{GROUND-PLANE DESIGN}

Fig. 1 shows the reference PIFA antenna and two designs where the groundplane has been modified.
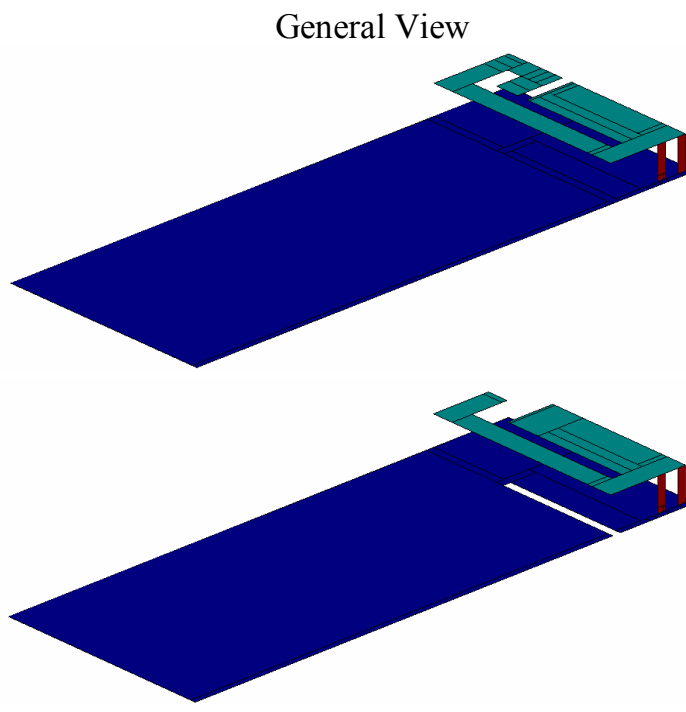

(a)

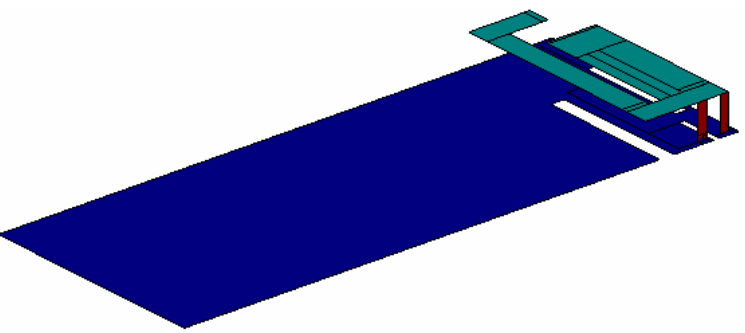

- $\quad$ PCB are $100 \mathrm{~mm} x$ 40mm

- $\quad$ PIFA heights are $6 \mathrm{~mm}$

- $\quad$ PIFA area are $39 \mathrm{~mm} x$ $10 \mathrm{~mm}$

(b)

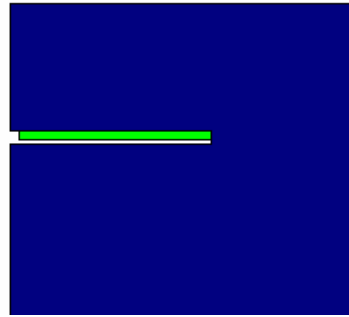

(c)

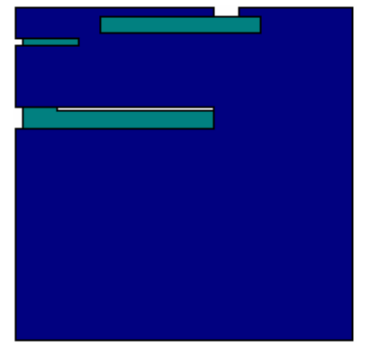

Fig. 1 a) PIFA antenna on a standard groundplane. b) PIFA on a slotted groundplane. c) PIFA on a multi-slotted groundplane $[1,2]$

Antennas a) and b) shown in Fig. 1 have been analyzed in [10]. The design rules were also presented in such a reference. To briefly summarize in here: design b) allows the dual-band GSM900 and $1800 \mathrm{MHz}$ PIFA of a) to become quad-band, that is, an antenna having a bandwidth covering GSM850, 900, 1800, and 1900MHz (SWR=3) with the same antenna volume thanks to a tuning effect on the groundplane. The purpose here is to enhance the previous technique to add more bands. The new bands are achieved by adding a parasitic resonator in the groundplane as a slot antenna. The position and length of the new slot in obviously determinant to obtain the enough coupling with the PIFA antenna and thus, obtaining more bandwidth [11].

\section{RESULTS}

The designs shown in Fig. 1 have been simulated using the Ie3D MoM commercial software. Simulation are interesting in order to obtain a good physical insight into the behavior of these structures, i.e., how the current flow on the groundplane. Once the design is complete, the antennas are implemented as shown in Fig. 2. The groundplane is printed on a FR4 substrate which is the common material used in cell-phones. The 
antenna is copper made using a milling machine. A plastic carrier (ABS) is used to correctly place the antenna on the groundplane.
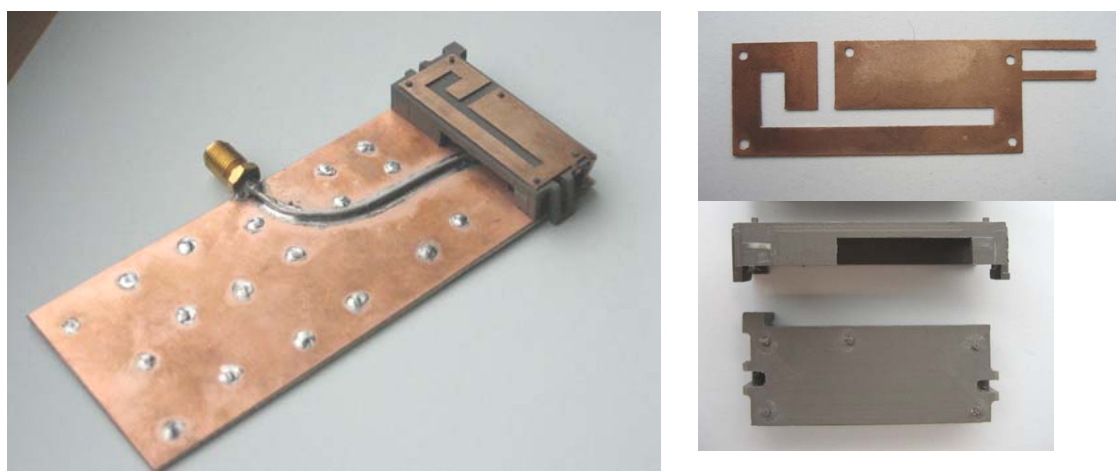

Fig. 2 Left: Built prototype. Right: antenna and plastic carrier
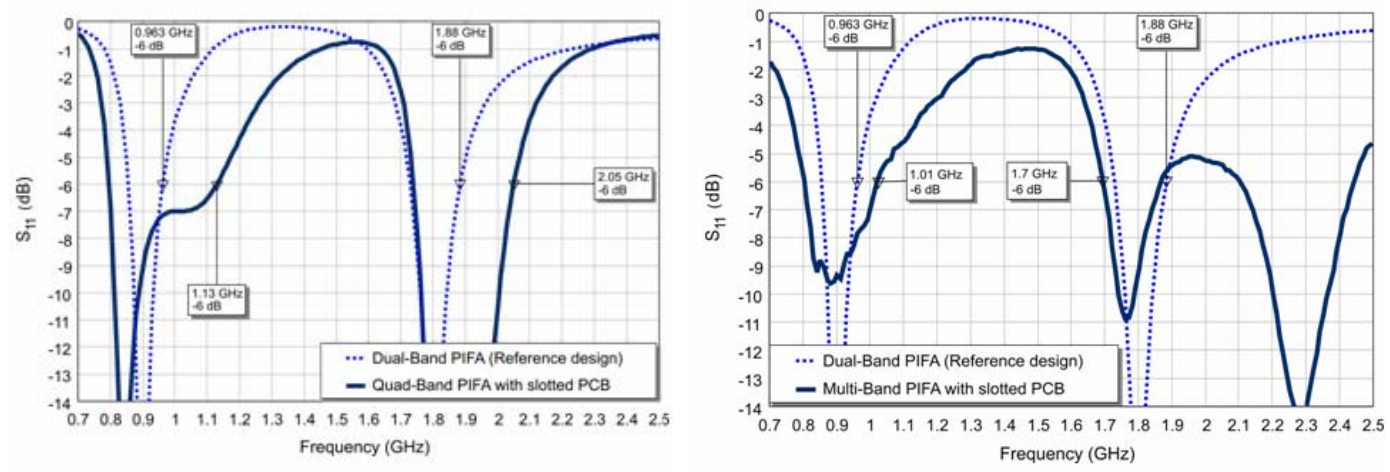

Fig. 3 Measured return loss. Left: design (a) and (b). Right: designs (a) and (c)

Fig. 3 shows the measured return loss for the antenna without manipulating the groundplane and for the two cases where the groundplane have been changed. It is clearly shown how the bandwidth is enhanced compared with the design without the groundplane manipulation. For the sake of brevity, further details will be given at the presentation.

Antenna efficiency, calculated as efficiency due to losses plus mismatch, is measured using pattern integration. Results are show in Table. 1. Dark cells show that the antenna efficiency is above a target objective according to this research project.

Table. 1 Measured antenna efficiency $\eta_{\mathrm{a}} \cdot \eta_{\mathrm{a}}=\eta_{\mathrm{r}} \cdot\left(1-\left|\mathbf{S}_{11}\right|^{2}\right), \eta_{\mathrm{r}}$ is the radiation efficiency

\begin{tabular}{|l|c|c|c|}
\hline \multicolumn{1}{|c|}{ Bands/ Antenna efficiency [\%] } & Design (a) & Design (b) & Design (c) \\
\hline GSM850 (828-890MHz) & $<40$ & $>70$ & $>60$ \\
\hline GSM900 (880-960MHz) & $>70$ & $>60$ & $>65$ \\
\hline GSM1800 (1710-1880MHz) & $<40$ & $>75$ & $>65$ \\
\hline GSM1900 (1850-1990MHz) & $>60$ & $>75$ & $>50$ \\
\hline UMTS $(1910-2170 \mathrm{MHz})_{\text {Bluetooth }^{(B)}(2400-2500 \mathrm{MHz})}^{<30}$ & $<10$ & $<40$ & $>55$ \\
\hline
\end{tabular}

\section{CONCLUSIONS}

It has been shown that the groundplane plays a significant role in mobile handset antennas. To improve bandwidth at low frequencies, the slotted groundplane permits 
tuning the fundamental mode of the PCB resulting in increasing the bandwidth of a PIFA antenna compared to a standard PCB. In addition, the slot on the PCB may be used as a radiator for the highest band. This paper shows how the slot contributes to radiation, thus enhancing the bandwidth at DCS. Based on these results, the proposed design enables improved functionality for quad-band and hexa-band cell-phones.

\section{ACKNOWLEDGEMENT}

This investigation is in the frame of University-Industry collaboration for Research in Antenna for Handset and Wireless Devices. This work has been financed by Fractus.

\section{REFERENCES}

[1] Patent pending WO2003023900

[2] Patent US7015868

[3] D. Manteuffel, A. Bahr, I. Wolff, "Investigation on Integrated Antennas for GSM Mobile Phones", Millennium Conference on Antennas \& Propagation, ESA, AP2000, Davos, Switzerland, April 2000.

[4] Patent US7164386

[5] J. Anguera, "Fractal and Broadband Techniques on Miniature, Multifrequency, and HighDirectivity Microstrip Patch Antennas", Ph.D Dissertation at Universitat Politècnica de Catalunya, Barcelona - Spain 2003.

[6] T.Taga and K.Tsunekawa "Performance Analysis of a Built-in Planar Inverted-F Antenna for $800 \mathrm{MHz}$ Band Portable Radio Units", IEEE Trans. Selected Areas in Communication, vol.SAC-5, n5, pp.921-929, June 1987

[7] T.Y.Wu and K.L. Wong, "On the impedance bandwidth of a planar inverted-F antenna for mobile handsets", Microwave Opt. Tech. Lett. Vol.32, pp.249-251, Feb.20, 2002

[8] P. Vainikainen, J. Ollikainen, O. Kivekäs, and I. Kelander, "Resonator-based analysis of the combination of mobile handset antenna and chassis," IEEE Transactions on Antennas and Propagation, Vol. 50, No. 10, October 2002, pp. 1433-1444.

[9] R. Hossa, A. Byndas, and M. E. Bialkowski, "Improvement of Compact Terminal Antenna Performance by Incorporating Open-End Slots in Ground Plane", IEEE Microwave and Wireless Comp. Lett. Vol14, nº, June 2004

[10] J. Anguera, I.Sanz, A.Sanz, A.Condes, D. Gala, C. Puente, and J.Soler, "Enhancing the performance of handset antennas by means of groundplane design". IEEE International Workshop on Antenna Technology: Small Antennas and Novel Metamaterials (iWAT 2006). New York, USA, March 2006.

[11] J.Anguera, L.Boada, C.Puente, C.Borja, J.Soler, "Stacked H-Shaped Microstrip Patch Antenna", IEEE Transactions on Antennas and Prop. Vol.52, n4, pp.983-993, April 2004. 